\title{
Fixada à parede, a coisa escrita: o cotidiano escolar em invenção e crítica
}

\author{
The written thing in the wall: \\ invention and criticism of school life \\ Fijado a la pared, lo escrito: \\ la rutina escolar en invención y crítica
}

MitSi PiNHEIRO DE LACERDA (iDa

\section{Resumo}

Este artigo tem por objetivo refletir acerca da invenção, reprodução e crítica de práticas no cotidiano escolar. Para isso, toma como referência teórica estudos de Michel de Certeau e Henri Lefebvre relacionados à vida cotidiana. Foi empregada, enquanto metodologia, a aplicação do método regressivo-progressivo proposto por Lefebvre através dos procedimentos de descrição, análise, regressão histórica e discussão a respeito de possibilidades. O desenvolvimento do texto comunica a análise que atravessa um artefato pedagógico comum, fixado à parede de uma sala de aula e encontrado em breve incursão a escolas localizadas no Noroeste do estado do Rio de Janeiro. Através do artefato pedagógico encontrado, acontece uma prática que dispõe de elementos presentes tanto em sua produção, quanto na reprodução e consumo. A descrição do artefato produz narrativas datadas historicamente, ressaltando a preservação de concepções anteriormente submetidas à crítica e sinalizando a invenção de outra realidade. No espaço escolar planificado, a busca regressiva e histórica que atravessa práticas e recursos didáticos, vai ao encontro de ideias que as delineiam e normatizam. Esta busca critica a persistência, na contemporaneidade, de produtos humanos já refutados. O estudo aponta para a possibilidade de a escola criar, através da análise crítica, regressiva e histórica, a compreensão acerca daquilo que produz e reproduz.

Palavras-chave: Cotidiano Escolar. Avaliação. Práticas Pedagógicas.

\footnotetext{
a Universidade Federal Fluminense (UFF), Niterói, RJ, Brasil. Doutora em Educação, e-mail: mitsipinheiro@id.uff.br
} 


\begin{abstract}
The article reflects about the invention, reproduction and criticism of daily school practices. Studies by Michel de Certeau and Henri Lefebvre related to everyday life was taken as a theoretical reference. The application of the regressive-progressive method proposed by Lefebvre through the procedures of description, analysis, historical regression and discussion about possibilities was used as a methodology. The text communicates the analysis that goes through a common pedagogical artifact fixed to the wall of a classroom and soon found a foray to schools located in the Northwest of the state of Rio de Janeiro. Through the pedagogical artifact found, there is a practice that has elements present both in its production, as in reproduction and consumption. The description of the artifact produces historically dated narratives, highlighting the preservation of concepts previously submitted to criticism and signaling the invention of another reality. In the planned school space, the regressive and historical search that crosses educational practices and resources, meets ideas that outline and standardize them. This search criticizes the persistence, in contemporary times, of human products already refuted. The study points to the possibility of the school creating, through critical, regressive and historical analysis, the understanding about what it produces and reproduces.
\end{abstract}

Keywords: School Life. Evaluation. Pedagogical Practices.

\title{
Resumen
}

Este artículo tiene como objetivo reflexionar sobre la invención, reproducción y crítica de las prácticas escolares diarias. Para ello, toma como referencia teórica los estudios de Michel de Certeau y Henri Lefebvre relacionados con la vida cotidiana. Como metodología, se utilizó la aplicación del método regresivo-progresivo propuesto por Lefebvre a través de los procedimientos de descripción, análisis, regresión histórica y discusión sobre posibilidades. El desarrollo del texto comunica el análisis que pasa por un artefacto pedagógico común, fijado a la pared de un aula y pronto encontró una incursión en las escuelas ubicadas en el noroeste del estado de Río de Janeiro. A través del artefacto pedagógico encontrado, existe una práctica que tiene elementos presentes tanto en su producción, como en su reproducción y consumo. La descripción del artefacto produce narraciones históricamente fechadas, destacando la preservación de conceptos previamente sometidos a crítica y señalando la invención de otra realidad. En el espacio escolar planificado, la búsqueda regresiva e histórica que cruza las prácticas y los recursos educativos cumple con las ideas que los describen y estandarizan. Esta búsqueda critica la persistencia, en tiempos contemporáneos, de productos humanos ya refutados. El estudio apunta a la posibilidad de que la escuela cree, a través de análisis críticos, regresivos e históricos, la comprensión de lo que produce y reproduce.

Palabras clave: Rutina Escolar. Evaluación. Prácticas Pedagógicas. 


\section{Introdução}

É recorrente a afirmação, seja proveniente de esferas acadêmicas ou de observações de seus usuários, que a escola brasileira perpetua, em seu interior, práticas e concepções que já foram refutadas e que, portanto, já deveriam ter sido abolidas. Em suposta indagação direcionada a sujeitos escolares, provavelmente eles não ofereceriam argumentos que sustentassem a presença, na atualidade, de premiações, castigos e competições nas escolas. Talvez não saberiam justificar, com consistência, a permanência do exame ou a fragmentação que estrutura tanto os currículos, quanto

o espaço e tempo acadêmicos. É provável que teriam dificuldades para argumentar favoravelmente em relação à lógica vertical e centralizadora da organização escolar, ou para defender o consumo de recursos didáticos de base tecnicista. Contraditoriamente, suas queixas geralmente se direcionam a estas estruturas aparentemente imutáveis, sem que sejam acompanhadas de sua superação. É perceptível, portanto, que orientações e práticas fundadas em concepções passadas e indesejadas, permanecem ativas nos cotidianos escolares.

Um rápido exame poderia, portanto, traduzir o cotidiano escolar enquanto espaço e tempo propício à perpetuação de concepções que não nos servem mais. Esta versão empobrecida do cotidiano o cristalizaria enquanto lugar para o qual são direcionados os resquícios da história humana, sem que nenhuma resistência ou inventividade os refutasse. Algo, contudo, se move.

$\mathrm{Na}$ escola, práticas são criadas, reproduzidas, reformadas, refutadas. No acontecer de um gesto inaugural residem resquícios de antigas proposições, assim como na retomada do que fora rechaçado, pode haver alguns traços autorais inscritos. É possível que, ao inventar uma atividade inédita e apresentá-la às crianças, a professora preserve orientações que talvez rejeitasse, se as pudesse perceber. Ao mesmo tempo, ao repetir diariamente uma prática desgastada, inscreve traços inaugurais que alimentam as aprendizagens, mas que poucos se detêm a conhecer. Se o exame das práticas tão somente estabelecesse distinção entre as que devem ser preservadas e as que devem ser banidas, teríamos algo como a manutenção dos jogos, da ida à biblioteca e dos passeios, e a extinção das cópias, das filas e das provas. Porém, como afirmado há pouco, algo se move. 
Este artigo tem por objetivo refletir acerca da invenção, reprodução e crítica de práticas no cotidiano escolar. Para isso, toma como referência teórica estudos de Michel de Certeau (1994) e Henri Lefebvre (1991a; 1991b) acerca da vida cotidiana. Em diálogo com a reflexão teórica há uma breve incursão à escola, orientada pelo método regressivo-progressivo proposto por Lefebvre (1986). Na escola, o encontro com uma prática alimenta a conversação: a produção e consumo de um artefato ${ }^{1}$ pedagógico fixado à parede de uma sala de aula.

O artigo é apresentado em três partes. A princípio, é empreendido um diálogo que aproxima o referencial teórico, epistemológico e metodológico. A segunda seção é dedicada à conversação acerca da invenção e crítica no cotidiano da sala de aula através da descrição de um artefato pedagógico. Por fim, são apresentadas as considerações finais.

\section{Vida cotidiana: inventividade e crítica}

É presumível que um olhar preguiçoso sobre a vida cotidiana leve um observador distraído a descrevê-la enquanto espaço homogêneo, repetitivo e pouco favorável à novidade. Não me oporia a tais comentários, mas, certamente, partiria ao encontro de um andarilho e de um inconformado para, como dizia José Saramago (1995), “dar a volta” neste olhar que se põe em perspectiva.

Pois foi ao percorrer as trilhas abertas por um caminhante que me entreguei a pensar na inteligência e na luta do dia-a-dia das pessoas comuns. Foi com o Certeau (1994) que abandonei a imagem estéril da vida para perceber a luta do fraco no jogo com o forte - um jogo quase sempre travado no campo deste e segundo sua própria normatividade, linguagem, conhecimentos e leis. Um jogo desigual, portanto, mas que nunca se finda, pois se o espaço é o domínio do forte, ao fraco restaria o tempo (CERTEAU, 1994). O fraco, segundo Certeau, dispõe do tempo, e por isso aguarda astuciosamente a ocasião propícia para se mover no campo do outro.

E o que se cria neste jogo entre fortes e fracos? O que permanece e o que irrompe enquanto novidade durante estas operações? Como são consumidos os produtos dispostos pelo forte? É importante notar que, em Certeau (1994), o

\footnotetext{
${ }^{1}$ Neste artigo, o termo "artefato" refere-se a objeto produzido manualmente e destinado a cumprir um fim específico.

Rev. Diálogo Educ., Curitiba, v. 20, n. 66, p. 1462-1485, jul./set. 2020
} 
consumo não se refere somente à consumação de mercadorias, mas também à invenção de outros usos para as práticas, linguagens, lugares, culturas, escritas, artes, religiões, leituras, teorias, misticismos, alimentos e tantos outros elementos que constituem a vida cotidiana. Para o nosso observador desatento, o que se produz é tão somente um modo de consumo fixado, o que contribuiria para a estabilização da vida cotidiana. É certo que isso se passa, mas com Certeau (1994) nos entregamos a pensar, sobretudo, a respeito do que se cria enquanto se consome.

Se há um modo de consumo fixado, há também a invenção de outros usos para o que está posto. Para Certeau (1994), a inventividade do fraco ocorre segundo a ocasião; ela opera astuciosamente em meio ao espaço configurado pelo conhecimento, linguagem e lei estabelecidos pelo forte. É ali, no campo do outro e sob sua normatividade, que o fraco inventa a vida e promove bricolagens ao usar, a seu modo, o que preservaria uma lógica fixada.

Em se tratando do cotidiano escolar — espaçotempo que alimenta a escrita deste texto - as brilhantes reflexões de Certeau dissolvem a imagem da escola organizada segundo estruturas universais, contribuindo para que outros usos criados por quem habita este espaço sejam observados e, muito especialmente, nos ajudem a aprender. Ao conhecer a escola, não é suficiente, portanto, observar o arranjo e os fluxogramas de sua estrutura: com Certeau aprendemos que, por entre esta engenhosidade, algo inaugural é inventado todos os dias - embora sem força suficiente para marcar o lugar ou capitalizar êxitos.

Se em Certeau (1994) vemos sobre a invenção da vida que atrevidamente se move por entre os alicerces da existência, Lefebvre (1991b) inscreve outras provocações ao analisar criticamente o cotidiano. Para ele, a crítica da vida cotidiana não se faz desde um exame externo e estéril, mas imbricada em sua historicidade com o intuito de criar, justamente naquilo que se apresenta enquanto miséria e alienação, as possibilidades para mudar a vida.

Seria, portanto, na miséria da vida de todos os dias que encontraríamos tanto os elementos para a sua crítica, quanto as possibilidades que permitiriam superar esta mesma vida, expandindo a "crítica que a vida cotidiana faz dela mesma, a crítica do real pelo possível, e de um aspecto da vida por outro" (LEFEBVRE, 1991b, p. 9, tradução nossa). Na dura realidade da vida cotidiana estariam, portanto, os elementos e condições para a superação. A crítica da vida cotidiana desde uma perspectiva Rev. Diálogo Educ., Curitiba, v. 20, n. 66, p. 1462-1485, jul./set. 2020 
lefebvriana envolveria não somente sua observação e desvelamento: esta crítica buscaria o conhecimento histórico e, nas contradições encontradas, as possibilidades de mudanças.

Lefebvre (1991a) aborda a realidade defendendo a ideia de que as contradições são postas pela coexistência de diferentes temporalidades. Penso que estas diferentes temporalidades aconteceriam em diferentes concepções, práticas, artefatos, regras, linguagens e em tantas outras invenções humanas gestadas em determinados tempos históricos e que, uma vez refutadas, já poderiam ter sido abolidas. Um grande achado reside aí: não obstante uma invenção humana já ter sido refutada, a ela pode ter sido concedida a permanência, atravessando e incluindo sua lógica em diferentes temporalidades. Em Lefebvre (1986), a percepção dos abismos que configuram as contradições não tem sido suficiente para que estas sejam superadas. Para ele, há que se observar também os desencontros de tudo o que habita a realidade, de forma a datar os elementos, explicar sua ocorrência simultânea e inaugurar os possíveis.

Voltemos a ele: o observador externo e desatento. Ele olha entediado para a vida cotidiana e apenas vê repetição. Diferente disso, Certeau caminha pela vida cotidiana e entende que seus passos atravessam o campo do outro, e que este campo é regido por lógicas e linguagens também provenientes do outro; ele, então, espera. Espera, calcula, inventa, avança, muda a direção ou até mesmo recua, mas não se entrega: ele não se resigna a ser um elemento de um cenário inerte.

Nesta mesma vida cotidiana encontramos Lefebvre. Ele olha para o espaço social inconformado com a alienação que aduba a cotidianidade, percebe o estado de conservação de diferentes tempos históricos e toda a miséria e ruína que arrastam consigo. Para ele, não seria somente a vida cotidiana que se repete: concepções, ideias, hegemonias, perversidades, ignorâncias e tantos outros elementos que constituem o caldo histórico, se mantêm. Então Lefebvre (1991b) se coloca como tarefa pensar e mudar o cotidiano que carrega em si o musgo bolorento da História. Para isso, ele propõe um método de exposição e análise que nos oriente a encontrar, na própria miséria da vida cotidiana, as condições para a sua superação.

Desde o mundo rural, Lefebvre (1986) destaca a dialética da dupla complexidade horizontal e vertical. Na complexidade horizontal é possível observar e descrever as diferenças presentes nas relações sociais, nas práticas, na configuração do espaço, no mundo do trabalho e em quaisquer outros elementos que constituam a Rev. Diálogo Educ., Curitiba, v. 20, n. 66, p. 1462-1485, jul./set. 2020 
realidade em determinado momento. Trata-se do estudo do "conjunto das condições" (LEFEBVRE, 1986, p. 166, grifo do autor) disponíveis à observação. Durante esta descrição de tipo etnográfico, as diferenças acontecem simultaneamente, sem que aparentemente sejam questionadas.

Com a complexidade vertical (ou histórica) é possível observar mais detalhadamente cada elemento descrito e mergulhar em sua historicidade, datando sua origem e explicitando as concepções que possibilitaram sua emergência. Aqui, cada elemento presente é trabalhado dialeticamente, revelando a coexistência de diferentes tempos históricos no mesmo "quadro". A simultaneidade desta dupla complexidade requer um método que lhe seja próprio, o que é oferecido por Lefebvre com o propósito de "desembaraçar o emaranhado de fatos" (1986, p. 170). Neste método — conhecido como "Regressivo-Progressivo", ele propõe três momentos:

a) Descritivo. Observação, porém munida da experiência e de uma teoria geral. Em primeiro plano: observação participante no local de pesquisa. Utilização prudente das técnicas de pesquisa (entrevistas, questionários, estatísticas).

b) Analítico-regressivo. Análise da realidade descrita. Esforço para datá-la com precisão (para não nos contentarmos com a constatação dos "arcaísmos" não datados, não comparados entre si).

c) Histórico-genético. Estudo das modificações desta ou daquela estrutura previamente datada, causadas pelo desenvolvimento ulterior (interno ou externo) e por sua subordinação às estruturas de conjunto. Esforço para uma classificação genética das formações e estruturas, no quadro do processo do conjunto. Esforço, portanto, para retornar ao atual anteriormente descrito para reencontrar o presente, porém elucidado, compreendido: explicado (LEFEBVRE, 1986, p. 173, grifos do autor).

Meu encontro com o método lefebvriano veio complementar uma disposição que há muito me habitava: compreender a "herança" da qual somos mantenedores, muitas vezes sem o perceber. Produzimos e consumimos um mundo repleto de produtos herdados, um mundo que ajudamos a expandir, em grande parte, com a reprodução desta herança. Mantenedores de criações que nós mesmos já rechaçamos, permanecemos há mais de um século calculando a suposta capacidade cognitiva do outro, aplicando orientações liberais na esfera pública, explorando a força de trabalho, negando a complexidade do real, subalternizando os pobres, afirmando relações escravocratas. São heranças renitentes que habitam o tecido social e cuja roupagem é alterada, esporadicamente, de forma a preservar seu disfarce.

De forma a detalhar a origem do material descrito neste artigo, informo que foram visitadas duas escolas públicas no noroeste do estado do Rio de Janeiro e registradas imagens provenientes de lugares diversos, localizados nas áreas externas e 
internas das instituições, em escalas micro e macro. Assim, foram fotografados, por exemplo, a fachada das escolas, o pátio, uma prateleira de livros na biblioteca, um talher da cozinha. No que se refere à apropriação do material de pesquisa produzido, as imagens foram olhadas desde as orientações postas pelo método lefebvriano, em sua natureza densa e lenta, de forma a trabalhar com descrições, com a datação de elementos e com a construção de "possíveis".

Trata-se de uma descrição que desenha um outro quadro daquilo que se mostra, um quadro que também se encontra em cena, mas que prescinde do "pintor" para ser desvelado. Isto demandou que as imagens fossem observadas por um olhar que acolhesse, em si, interlocuções provenientes de diferentes campos do conhecimento e abarcassem diferentes temporalidades registradas nas fotos.

Para compor a redação deste artigo, apenas uma foto foi escolhida: a imagem de um artefato pedagógico que se encontrava fixado à parede de uma sala de aula. Não foi considerada relevante a exibição desta imagem no corpo do texto, uma vez que a mesma não se constitui enquanto objeto de estudo. $\mathrm{O}$ tratamento oferecido à imagem ocorreu na descrição que conduziu às marcas de historicidade. O resultado da pesquisa registrou criticamente diferentes temporalidades presentes em uma mesma realidade, fomentando a elucidação de "possíveis" e oferecendo à escola o exercício de encontrar, em si mesma, dimensões a serem questionadas.

\section{As paredes da escola}

Lefebvre (1991a) defende a ideia de que vivenciamos diferentes temporalidades concomitantemente, e isto é bastante instigante: vivemos a modernidade, mas, junto a ela, carregamos conosco concepções, artefatos, práticas, relações sociais e políticas que lhe são anteriores. Estas "heranças" que insistimos em manter se infiltram na contemporaneidade, por vezes, sob disfarces — uma herança disfarçada. Uma herança que é própria para ser discutida, mas que, infelizmente, não pode ser devolvida.

Para exemplificar, busco mentalmente na escola, de forma aleatória, uma cena que possa ser facilmente reconhecida: a hora da merenda. Neste momento tão familiar a (quase) todos, é possível encontrar uma criança aguardando na fila por seu prato de sopa, enquanto outra criança abre sua lancheira, em busca de um petisco Rev. Diálogo Educ., Curitiba, v. 20, n. 66, p. 1462-1485, jul./set. 2020 
industrializado. Ambas crianças habitam, física e contemporaneamente, o mundo moderno. Contudo, entre elas há distinções forjadas por suas condições materiais de vida e também pelo consumo daquilo que seria o "signo do moderno": a lancheira e o petisco industrializado. Enquanto uma criança se mantém na fila denunciadora do lugar social imposto a ela, a outra criança, aparentemente, foge deste cenário, sem perceber, talvez, que sua condição seja a mesma.

A contradição não estaria tão somente na diferenciação econômica entre as merendas, mas também na simultaneidade do preparo desigual dos alimentos, e em seu consumo. A sopa propiciou, a quem a preparou, um processo no qual a cozinheira foi a autora, e a sopa, sua “obra”. O petisco industrializado fez o contrário, produzindo o desejo, e a consumidora. Oferecidos às crianças, sopa e petisco inscrevem quem os consome em um lugar social mais ou menos privilegiado. A observação da produção e do consumo, contudo, invisibiliza um componente importante: a coexistência contraditória de práticas datadas historicamente, em uma contemporaneidade que carrega, em si, lógicas tecidas por relações sociais distintas. Daí a relevância por se observar, em coexistência, artefatos, concepções e práticas cuja gênese remonta a diferentes temporalidades. Neste artigo, convido à observação de um artefato no qual se depositam, eloquentes, traços da História.

Renitentemente íntimo da linguagem poética, Lefebvre ensina que a palavra, mesmo proferida em outras temporalidades e espacialidades, é algo encarnado e revelador de uma presença, já que sua principal referência é o desejo (1991a, p. 188). Para ele, a palavra é hot. Isso implica em que a palavra provoca a palavra, e também silêncios inundados de palavras, e palavras que se deslocam no tempo e no espaço, e palavras que hibernam e renascem como mesmas ou como outras, mas que jamais decalcam sua matriz. Puro movimento e permanente aquecimento, são próprias da criação e do devir.

No escrito, Lefebvre (1991a) percebe a eterna semelhança e a recorrência, em uma entonação que lhe atribui propriedades de "coisa". A coisa escrita somente pode ser aquecida por um leitor. É na leitura que acontece a conversão da ausência em presença, com invenção de sentidos, mediados pelo desejo de quem lê. O desejo proveniente da palavra rompe a barreira gélida do escrito, e "se a coisa escrita se põe a tremer, se sua pureza se turva e ganha, por meio dessa turvação, uma outra transparência que lhe tira suas qualidades de coisa (mental e social), o efeito se multiplica" (LEFEBVRE, 1991a, p. 189). 
Enquanto a ruptura e o estremecimento da "coisa escrita" acontecem lindamente no encontro do leitor com a literatura, é rara sua ocorrência no escrito que foi submetido à vivissecção e posto a serviço do funcionalismo. Encontrada nas paredes das escolas, este tipo de "coisa escrita" diz mecanicamente o mesmo, determinando o consumo do espaço e regulando as trajetórias.

As paredes das escolas são postas a serviço de uma arquitetura panóptica (FOUCAULT, 1987), intencionam circunscrever o lugar no qual o espaço escolar é praticado (CERTEAU, 1994), sinalizam o espaço no qual as relações sociais de produção são reproduzidas (LEFEBVRE, 2000) e ainda guardam uma função modesta e potente: servem como suporte para a "coisa escrita". Nas paredes das escolas encontramos diversos portadores de textos que nebulam o espaço percebido, ao intensificar o espaço concebido e negligenciar o espaço vivido ${ }^{2}$. As paredes das escolas estão repletas de escritas-burocracia, quando poderiam expor "obras".

Referindo-se a uma sociologia da escrita e à burocracia que trama as opressões da cotidianidade, Lefebvre (1991a) destaca a “coisa escrita” em sua natureza opressiva e não violenta. Enquanto lei que configura racionalidades, a coisa escrita se sobrepõe à fala, estabelecendo e fixando sentidos. Ato fundador e perene no plano institucional, “ela se insere na prática social para captar a obra e a atividade, organizando-as" (p. 166). Atenta aos movimentos instituintes, ela os toma e regula desde sua origem, planificando o que se expressa na vida cotidiana. Inocentemente disfarçada como cartaz pendurado na parede ou plaquinha fixada à porta, a coisa escrita oprime sem fazer alarde. Ela alicia conversações, programando e substituindo a vida, pois "toma como referência 'qualquer outra coisa', como costume, prática, acontecimento, depois ela se torna referência" (LEFEBVRE, 1991a, p. 166, aspas do autor).

Pelas paredes das escolas é possível encontrar, expostos, diversos artefatos de natureza administrativa, pedagógica, extracurricular, gerencial e outros. São avisos, regras, textos, proibições, felicitações, combinados, imagens, registros de frequência, do clima, dos aniversários, alfabetos, numerais, atividades didáticas, efemérides, mensagens, citações de autores, sinalizações, cardápios, horários. Quanto a isso, é

\footnotetext{
2 Segundo Lefebvre (2000), há três níveis de prática espacial, dialeticamente imbricadas. No vivido acontecem as vivências instituintes (afetos, corporeidade, linguagem), enquanto no concebido se planifica a versão institucional (significações sócio-políticas) e é onde se reproduzem as relações sociais de produção. O espaço percebido seria o nível de entendimento das contradições postas entre o vivido e o concebido.
}

Rev. Diálogo Educ., Curitiba, v. 20, n. 66, p. 1462-1485, jul./set. 2020 
preciso que "chamemos a atenção para a forma da escrita: a recorrência. A coisa escrita permite a cada instante voltar atrás” (LEFEBVRE, 1991a, p. 168).

Atenta às manifestações que se processam na vida escolar, a coisa escrita as captura tacitamente, reduz, modela e transmuta, fazendo parecer que ela, a coisa escrita, é tão somente parte do que se passa. Mas não é. Permanentemente exposta ao olhar, "ela parece inocente e abusa da inocência do leitor. Daí provém o poder do escrito (e do impresso) sobre os ingênuos e sobre alguns outros. A coisa escrita provoca a adesão. Sua fixidez fascina" (LEFEBVRE, 1991a, p. 169).

Isto me remete a um desenho com o qual eu fui presenteada recentemente, após visitar uma classe de alfabetização. Passados alguns dias da minha visita à escola, me foi entregue um desenho no verso do qual fora escrita uma mensagem carinhosa e convidativa ao retorno e à continuidade do diálogo. Aquilo me afetou. Uma criança havia retratado o nosso encontro em sua sala de aula. Que me perdoem os exageros, mas aquele desenho era um Velázquez ${ }^{3}$. O desenho não estava assinado, mas provavelmente o (a) artista se encontrava representado (a) na obra.

Ao fundo, os cartazes com os numerais, o alfabeto, o relógio com indicações de uso, os desenhos e textos pendurados ao quadro de escrever, cartazes de aniversário e clima, o globo e, também, o registro de um dos momentos vivenciados por nós que compúnhamos este quadro. O professor da turma foi retratado sentado ao chão, ao seu lado a monitora e, à mesa, eu. Somos três adultos na cena, e não é possível ver nossas feições. Em pé, coletando e distribuindo as atividades, as crianças olham para fora do quadro. Olham para a observadora, olham para quem olha: neste caso, para mim, uma vez que eu era a destinatária desta obra de arte. Parece que vejo Foucault (1999), a sorrir.

\footnotetext{
3 Pintor espanhol, Séc. XVII, autor, dentre outras obras, de "As meninas". Rev. Diálogo Educ., Curitiba, v. 20, n. 66, p. 1462-1485, jul./set. 2020
} 
Figura 1 - A visita à escola

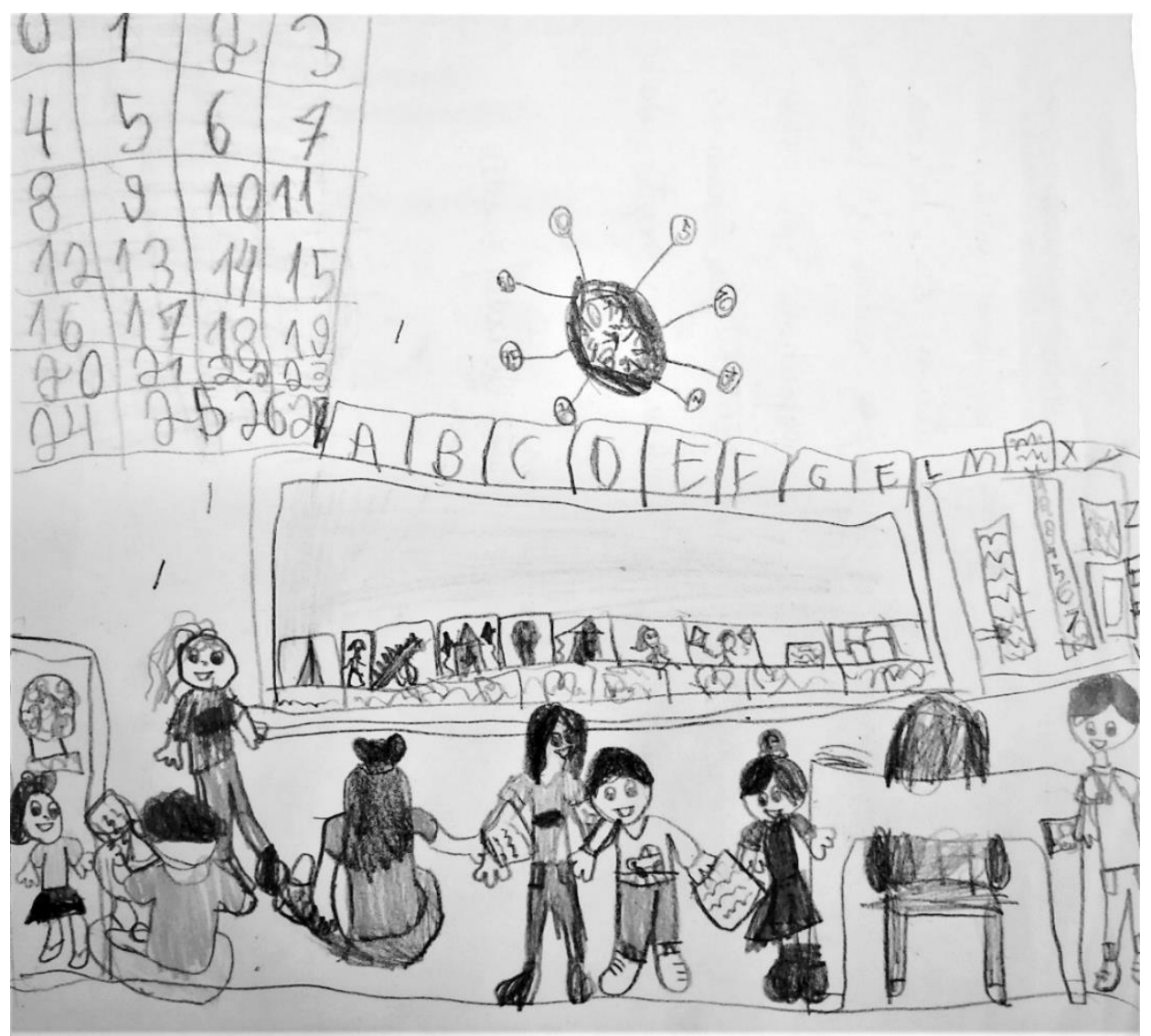

Fonte: Arquivo pessoal (2019).

A criança autora do desenho realizou o duplo movimento de observadora externa e interna, registrando detalhadamente o acontecer do espaço naquele momento, com o que nele havia de rigidez e movimento. Tecendo o espaço por iniciativa própria, as crianças se moviam e ajudavam no manejo das folhas de papel após verificarem que nós, os adultos, estávamos embaraçados com a tarefa. Praticantes astuciosas, as crianças adentravam o campo regulado pelo outro ao notarem a fragilidade da regulação (CERTEAU, 1994).

Exposta nas paredes, mantinha-se inerte a coisa escrita retratada no desenho: tratava-se da reprodução de informações fragmentadas que também se encontram presentes em outras salas de aula. São informações reproduzidas à exaustão, desconectadas dos contextos que alimentam seus sentidos; informações que pouco se prestam a provocar o pensamento e que, como produtos, são tão somente replicados. Sua ocorrência quase generalizada em classes de alfabetização dissolve o inócuo de sua presença, ao mesmo tempo em que oculta a engenhosidade de sua origem e as lógicas subjacentes. 
A inércia do artefato fixado à parede da sala de aula inibe a percepção de sua gênese, das concepções que o orientam, do que produz, daquilo que condiciona e das possibilidades de superação que contém. Se é fato que nenhuma palavra habita inocentemente este mundo, talvez seja preciso aprender a observar o que se mascara nas paredes das escolas, escavando sua complexidade vertical para saber por onde ela - a palavra - andou. A escrita inaugura uma nova consciência, mas também "se torna um princípio de hierarquização social que privilegia ontem o burguês, hoje o tecnocrata" (CERTEAU, 1994, p. 320).

Em uma das escolas visitadas durante este estudo me deparei com um artefato, dentre tantos expostos em uma sala de aula. Fora confeccionado com uma caixa retangular encapada com papel camurça preto, e esta caixa estava pendurada na parede, próxima à porta, sobre um cabo de vassoura também preto, que lhe oferecia suporte. Podia ser visualizado por quem chegava, por quem saía e por quem permanecia no lugar. Posição estratégica.

Distribuídos na frente da caixa, com exatidão métrica, havia três recipientes redondos, provavelmente potes de manteiga reciclados. Os três recipientes foram pintados com tintas verde, amarela e vermelha, e dispostos verticalmente nesta ordem. No interior do recipiente verde, estava escrito "vencer"; no amarelo, "pensar"; e no vermelho, "mudar". Em cada um desses potes estavam fixados alfinetes desde os quais pendiam nomes - certamente os nomes das crianças que estudavam nesta classe. Por baixo dos potes coloridos, o nome do artefato: "Semáforo do Comportamento". Tudo muito caprichosamente bem feito, com os nomes de quase todas as crianças pendurados no verde, com exceção do Jorge ${ }^{4}$, que este estava pendurado sozinho no potinho vermelho — "mudar".

Atravessando verticalmente o artefato em busca de algumas concepções presentes, encontramos, na História, momentos que sustentam sua existência. Este artefato carrega em si uma lógica comportamental que visa o controle, a submissão e a ordenação dos corpos. O pequeno Jorge, único habitante do sinal vermelho, era publicamente chamado à "mudança". A coisa escrita e inerte dizia permanentemente a todos que o comportamento de Jorge não era adequado à configuração daquele

\footnotetext{
${ }^{4} \mathrm{O}$ nome é fictício.

Rev. Diálogo Educ., Curitiba, v. 20, n. 66, p. 1462-1485, jul./set. 2020
} 
espaço, e que para merecer a polarização até o potinho dos vencedores, precisava se ajustar à lógica requerida.

Em meio a este percurso de "mudança", Jorge poderia se resignar à expiação no potinho do "pensar". Curioso é que o estágio no potinho do "pensar" implicaria na negação de si e na adoção da conduta apropriada à sua ascensão ao potinho dos vencedores. Nesta engenhoca, o pensamento - algo de mais fabuloso que nos acontece - fora reduzido a um estágio com entonações sacras de purgatório, considerado como uma boa oportunidade oferecida ao "desviante". Mais uma vez, é bom que se busque na verticalidade histórica alguma compreensão acerca do espaço que habitamos.

Uma vez regulado pelo dogma religioso no período medieval, o pensamento foi orientado, no decorrer histórico da modernidade, pela racionalidade cientificista, por ideais liberais, pelas relações de produção, pela complexidade e por tantas outras influências sociais, políticas, religiosas e econômicas. A natureza em expansão do pensamento — fluxo da criação e alimento da inventividade — também tem sido, em grande parte, condicionada, e, neste artefato escolar, o "pensar" implicava no momento de purificação da culpa, para o acesso à "vitória".

"Pensar", nesta lógica, implicaria em sujeitar-se a negar a diferença e a inibir a novidade. Implicaria em pensar o que o outro quer que seja pensado, para que o pensador se assemelhe a ele. Daí, então — quem sabe? — vencer. O nome de Jorge se destacava ao ser exposto isoladamente. Um dia, na História que miseravelmente fizemos acontecer, sujeitos escravizados foram expostos em troncos, mulheres nomeadas bruxas tiveram seus corpos violentados à vista de multidões, cientistas foram ridicularizados publicamente por ousar substituir dogmas por explicações. Embora estas atrocidades não sejam mais possíveis e embora o potinho do "pensar" não disponha de tamanha perversidade, sua dinâmica conceitual é a mesma.

No movimento da aula, o "semáforo do comportamento" se mantém em silêncio eloquente. Fixado a um canto, materializa a lógica comportamental que, mecanicamente, ajusta aprendizagem e desenvolvimento ao controle do corpo. Cristalizado no potinho vermelho, o nome de Jorge é sinônimo de "estímulo" para a "mudança", funcionando como biopoder e biopolítica (FOUCAULT, 1987) voltado para ele e toda a sua turma. Junto às lições de português e matemática, o artefato ensina às crianças que há um — e somente um — comportamento aceitável. 
Mas, a suposta inadequação do corpo do menino à disciplina escolar seria suficiente para sua exclusão? Ali está escrito tratar-se de um semáforo do "comportamento". Antes de terem seus nomes distribuídos entre os potinhos do "mudar", do "pensar" e do "vencer", estas crianças foram observadas, classificadas, hierarquizadas. Seu comportamento figura enquanto elemento central a alimentar estas distinções, mas é provável que outros fatores colaborem, mesmo que tacitamente, com esta equação. Dentre estes fatores, podemos pensar acerca da origem social de cada criança, de sua etnia, do status usufruído por cada família em sua relação com a escola e também com os resultados da avaliação da aprendizagem.

A localização de cada criança no "semáforo do comportamento" também não coincidiria com os resultados atribuídos a ela desde a avaliação da aprendizagem? Não me foi possível ter acesso ao rendimento escolar de Jorge, mas fui informada, pela professora, de que ele "não tem jeito, não quer saber de nada". Na escola, a avaliação não ocorre tão somente em momentos sinalizados pelas cercanias institucionais: atravessa toda a prática pedagógica e interfere fortemente junto às relações e constituição do espaço escolar. É comum que muita atenção seja conferida às ações avaliadoras instituídas (através de suas metodologias, periodicidades, pesos e medidas), ocultando parcialmente outros movimentos que, se não configuram diretamente o rendimento escolar, o alimentam continuamente.

A avaliação atravessa as relações entre ensino, aprendizagem, família, escola, sociedade, professora e estudantes (PERRENOUD, 1999) - embora este atravessamento nem sempre se encontre formalmente documentado nos resultados oficiais da escola. Por se destinar ao registro do "comportamento", o artefato observado se isenta do gerenciamento da administração escolar, e o que ele informa, não é oficialmente incluso no aproveitamento de cada estudante. Seu caráter pragmático, comprometido com a manutenção da ordem através da vigilância, disfarça os diferentes consumos (CERTEAU, 1994) que lhe são conferidos pela professora, crianças, suas famílias e agentes pedagógicos da escola.

Retomando as mudanças ocorridas historicamente na prática do exame, Barriga (1999) afirma que, a princípio, a avaliação fazia parte do método e favorecia o acompanhamento das aprendizagens e a problematização do ensino. Posteriormente, a avaliação afasta-se do método e ocupa lugar privilegiado junto à certificação — ou seja, a avaliação surge sob o formato de diversos instrumentos que Rev. Diálogo Educ., Curitiba, v. 20, n. 66, p. 1462-1485, jul./set. 2020 
mensuram a aprendizagem e legitimam a promoção ou a retenção de estudantes. Ora, se olharmos cuidadosamente para o "semáforo do comportamento" podemos supor que, no que se refere ao método, ele se insere tacitamente enquanto procedimento de vigilância e controle — além de oferecer elementos para a certificação, ao influenciar a atribuição de resultados individuais.

A descrição do artefato nomeado como "semáforo do comportamento" abre caminhos através dos quais podemos nos aprofundar verticalmente na compreensão histórica das concepções que determinam sua existência. Buscando no método lefebvriano, entendo que o conhecimento vertical das concepções e práticas que constituem o espaço, coexiste dialeticamente com o possível. O entendimento das lições contidas no quadro regulador do comportamento pode provocar sua negação e conduzir ao diálogo e construção coletiva de outras possibilidades ao corpo, ao ensino e à aprendizagem.

Para que o "semáforo do comportamento" fosse planejado e executado, foi necessário que alguém acionasse, de longínquas paragens, ideias relacionadas ao controle, à centralidade do poder, à exposição pública do erro, à eliminação das diferenças, à homogeneização e à avaliação. Este artefato diz de um mundo que se configura segundo a perspectiva de que a educação é um ato de produção, e que a produção requer a ordem, e que a ordem é algo que se manifesta no corpo, e que este corpo precisa se sujeitar a uma norma. A manutenção dos nomes das crianças no potinho verde, dos “vencedores", jamais sustentaria, sozinha, este projeto de controle e poder. Foi preciso, portanto, destacar o seu oposto no potinho vermelho e ofertar recursos para a conversão no potinho do "pensar".

Neste momento me vem Paulo Freire (1997) e sua insistência acerca da inexistência de neutralidade no ato pedagógico. Um lindo artefato colorido fixado à parede não dispõe de existência incólume, pois que ele representa algo. Ele arrasta em si concepções que forjaram momentos históricos, fazendo com que o presente seja atravessado por ideias que já não nos servem mais. A observação interessada deste inocente e lúdico artefato convida a escavar, nos palimpsestos da História, argumentos que sustentam e direcionam sua construção e uso.

Sendo o método regressivo-progressivo um método de investigação e exposição, é importante que se bote reparo a todo este movimento de descrição, análise e elucidação de possíveis. O “semáforo do comportamento" se encontra Rev. Diálogo Educ., Curitiba, v. 20, n. 66, p. 1462-1485, jul./set. 2020 
fixado na sala de aula. Uma olhadela distraída constataria a existência de um artefato lúdico utilizado por várias outras professoras, em outras salas de aula. Seria tão somente mais um artefato a compor o espaço da sala de aula, juntamente com os cartazes do clima, do calendário, dos aniversários, das presenças azuis de meninos, e cor-de-rosa de meninas. A descrição do tipo etnográfico, ao produzir uma descrição densa, favorece a busca de entonações presentes naquilo que se descreve. Nos vastíssimos e rizomáticos caminhos que percorrem a História, encontramos as fundações daquilo que nos propomos a compreender.

A tarefa por mergulhar verticalmente na História nos coloca defronte a uma miríade de caminhos possíveis. Dentre eles, penso que o "semáforo do comportamento" buscou algumas de suas ideias na história da avaliação. Com isso, firmou seu status de veracidade ao se apresentar enquanto dispositivo a serviço do exame, colocando, em disfarce, a hierarquização e exclusão provenientes desta prática. Ao alinhar o comportamento ao corpo e ao legitimar bases observáveis para a mecânica entre estímulos e respostas, trouxe novamente o que já fora amplamente criticado nas teorias behavioristas: que o bom comportamento estaria relacionado à inércia e à obediência do corpo. De forma a ostentar trajes que fossem socialmente aceitos, buscou em algumas empobrecidas representações da ludicidade, indicações de que o lúdico precisa ser expresso em belas formas e cor. Garantindo à professora a função de discernir acerca dos nomes a serem expostos em cada um dos potinhos, o "semáforo do comportamento" contribuiu para atravancar a pedagogia democrática e dialógica, afirmando a centralidade docente.

Um artefato pedagógico, lúdico e funcional. Não podemos negar. O material utilizado em sua produção - caixa, cabo de vassoura, potes de manteiga atravessou um processo no qual lhe foi subtraída sua função inicial, e atribuída outra. Com Certeau (1994) entendemos que o trabalho com a sucata seria uma espécie de metáfora que remete a produtos criados por praticantes no campo do forte, sem que sua racionalidade imposta, seja empregada. A sucata estaria a dizer da invenção de outros usos para aquilo que dispõe de um tipo específico de consumo. Ao compor o "semáforo do comportamento" a professora não somente manipulou a sucata, como afirmou traços de autoria com as escolhas que fez. Transformou um pote de manteiga em spot de luz. Operou com bricolagens. Pensou, criou, produziu. 
Junto a isso, contraditoriamente, reproduziu um modelo, alimentou uma concepção com a qual talvez nem se alinhe, introduziu em sua prática um artefato que não se pretende favorável às aprendizagens. Entusiasmada, talvez, com a ideia de também possuir um recurso didático que vinha sendo amplamente utilizado, não percebeu que construiu um artefato que prontamente se coloca a serviço do controle, do exame, da classificação, da exclusão, da vigilância, do silenciamento.

Pois bem. Uma vez descrito e analisado, é preciso inventar algo a partir disso - e são muitas as lições. Enquanto descrevia e escavava as influências presentes, pensava. O que é possível desde todo este trabalho? O que a coisa escrita e exposta nas paredes da escola diz, reproduz, nega e cria? Um detalhe: o que se encontra fixado à parede é a reprodução de algo, ou uma obra de arte? Quem a desejou, pensou, inventou e criou? O que acontece, em termos de expansão da consciência e da prática de liberdade, quando alguém reproduz um modelo ou cria algo desde seu desejo? São tantos artefatos fixados na sala de aula! Quais deles são inaugurais, quais deles são criações geradas no calor de conversações dialógicas? O que se passa quando a criança observa uma série de folhas de papel penduradas no varal, com o mesmo desenho impresso? Quais são os usos (CERTEAU, 1994) conferidos pela criança àquilo que é formatado a partir de um modelo? Nosso artefato - o "semáforo do comportamento" - está presente em várias salas de aula. Seu modelo está disponível na Internet. Basta copiar. Será que quem reproduz um modelo percebe que, ao fazê-lo, também reproduz concepções, práticas e orientações com as quais talvez nem esteja de acordo?

A observação do "semáforo do comportamento" inscreve sua crítica, a busca de suas influências históricas e também o desenho de possibilidades. Faz pensar com densidade que a neutralidade é, ela própria, uma ideia repleta de intenções. Este artefato, fixado à parede, diz coisas. Curioso é que, ao dizer coisas, coloca em suspeição também outros artefatos, cartazes, dispositivos pedagógicos e até mesmo a organização da sala de aula. Ao examinar desconfiadamente o "semáforo do comportamento", passo a duvidar de todo o resto, e duvidando, entendo que preciso dialogar para compreender. Como envolta em uma prática etnográfica, passo a perscrutar com estranhamento o que me parecia familiar. Vejamos: as letras do alfabeto fixadas sobre o quadro de escrever. Ora... Se sou uma professora que trabalha desde uma dimensão discursiva e interacionista, defendendo que a alfabetização só Rev. Diálogo Educ., Curitiba, v. 20, n. 66, p. 1462-1485, jul./set. 2020 
faz sentido no e com o texto, por que preservo estas letras isoladas fixadas à parede? E mais: as atividades reproduzidas e distribuídas às crianças diariamente. Pois bem. Se em minha prática docente invisto na ideia de que o currículo é tecido na interação e na conversação, e que os currículos só fazem sentido se os sentidos forem tecidos por quem os tece, por que reproduzo estas atividades todos os dias? Por quê?

$\mathrm{Na}$ sala de aula, ao aprofundarmos a descrição e análise histórica do objeto observado, outros objetos são "contaminados" com procedimentos similares, a saber, a especificação e datação de concepções que forjaram sua (re)produção. Daí que a sala de aula reproduzida, ano após ano, faz estremecer seus referenciais e provoca a urgência da criação. Quando se entende que o espaço tem sido tão somente o mimetismo de algo transferido por outro, se entende também do desejo por se criar este espaço com quem o habita: as crianças.

A dialética inerente ao método regressivo-progressivo imprime movimento ao pensamento, enquanto produzimos e reproduzimos o espaço. Continuamente programado, o espaço disponibiliza sinais nem sempre explícitos que adentram as condutas e amortecem a criação. Buscando verticalmente na História das ideias humanas, encontramos também os fios com os quais tecemos a liberdade. Pura utopia, movimento complexo e permanente, em busca de uma vida bela.

As paredes das escolas estão repletas da coisa escrita. Em grande parte, a escola produz o paradoxo de confinar o imensurável da escrita na advertência, sinalização e reprodução de ideias que já foram refutadas. As importantes discussões sobre gênero já denunciaram há tempos o uso das cores enquanto marcadores, mas a placa do banheiro dos meninos permanece azul. As não menos importantes discussões sobre currículos já nos permitiram pensá-lo enquanto expressão dos sujeitos, mas nas salas de aulas ainda encontramos os cantinhos da leitura, da matemática e das ciências. Já é amplamente sabido acerca da coerção, competitividade, hierarquização e exclusão da avaliação, mas os cartazes com estrelinhas douradas sobrevivem. Há décadas nos foi apresentada a crítica ao tecnicismo, mas pelas paredes das salas de aulas ainda persistem os quadros com os dias da semana, o clima, a frequência de meninos e meninas. Concomitante aos estudos referentes à alfabetização — que a compreendem enquanto processo discursivo - as letras do alfabeto insistem em se mostrar isoladas, coladas sobre o quadro de escrever. Ao ingressar no espaço escolar, a criança encontra um produto pronto a ser consumido. 
A observação do que se encontra disposto pelas paredes escolares revela, como ensina Lefebvre (1986), a coexistência entre o que se foi, e as possibilidades de futuro. Nesta coexistência se sobrepõe o império da coisa escrita — dessa escrita desprovida de vida, de pensamento — mas contraditoriamente berço para alternativas. O que fazer? Eliminar todos os artefatos que se encontram dispostos nas paredes das escolas? Certamente não, pois que são eles que convidam à tríade dialética, que convidam a olhar para a prescrição, a perceber o seu contrário e a aventar possibilidades de superação.

Como seriam, então, as escolas, se imaginadas por quem as habita? Poderíamos desenhar estas escolas imaginadas, desprovidas do modelo convencional? É suficiente que se retirem os cartazes das paredes, quando a lógica da coisa escrita já se encontra instalada nas práticas da cotidianidade e no pensamento? Quando falamos do espaço escolar e defendemos o direito à escola, nos referimos a mudanças na estrutura física e organizacional, ou lutamos pelo desenvolvimento das relações sociais? Como seria esta escola jamais vista anteriormente, a qual se materializaria desde o que se processa entre as pessoas?

Durante a aplicação do método regressivo-progressivo é preciso que se faça uma espécie de “descrição densa” (GEERTZ, 1989) acerca da realidade estudada. No que se refere a esta pesquisa, foram produzidas imagens do cotidiano escolar, mas sua descrição, no corpo deste artigo, se aproximou tão somente da "coisa escrita" fixada às paredes, mais especificamente, de um artefato "pedagógico". Os limites do artigo não permitem abordar detalhadamente todo o material produzido durante a pesquisa, mas isso não fragilizou o objetivo de pensar sobre a inventividade e a reprodução que tecem o cotidiano escolar.

Isto porque o movimento empreendido durante a discussão relacionada ao artefato não pressupôs seu julgamento, nem tampouco o resultado exposto se configurou como um modelo. Não é válida a reprodução do olhar depositado neste caso, e seu deslocamento até outros que lhes sejam semelhantes. O que se oferece, aqui, é tão somente a comunicação do gesto: o gesto de ver nas coisas, nas práticas, nas linguagens e nas relações tanto as suas histórias, quanto as concepções que as orientaram e que insistem em permanecer. Trata-se de disseminar um gesto que abarque em uma mirada o presente, o passado e sua superação. Práxis, portanto. 
Com o método regressivo-progressivo aprendemos a olhar para o cotidiano escolar e a desvelar, criticamente, ideias que não são contemporâneas, mas que insistem em orientar o que se faz. Deste modo, as filas com as crianças, a organização das salas de aula, as relações entre famílias e escola, a merenda, o recreio, a fragmentação do espaço e tempo escolar, o material didático, a presença de hinos e orações na escola laica, os currículos, a avaliação, a burocracia — tudo se expande e nos move a buscar, na História e no pensamento crítico, o contexto político, sociocultural e científico próprio de sua origem.

A persistência de concepções que já foram refutadas, junto às práticas escolares contemporâneas, dificulta enormemente o desenvolvimento das relações sociais que se processam nas escolas. Em verdade, elas se impõem desde a lógica da modernidade e empregam como justificativa um forte argumento da cotidianidade: a repetição que se pretende desprovida de mudança. Com isso, ordenações gestadas pelo pensamento liberal, pelo mercado, por dogmas diversos, pelo colonialismo, pela mensuração da cognição, pelo tecnicismo e por tantas outras ideias humanas ${ }^{5}$, sobrevivem em roupagens modernas que lhes asseguram sua vitalidade.

\section{Considerações finais}

Em grande parte influenciada por Henri Lefebvre e atravessando brevemente a produção teórica de outros autores, me foi permitido compreender que a busca regressiva e histórica desde o espaço escolar planificado sinaliza concepções que delineiam práticas e normatizam condutas. Esta busca coloca frente a frente a coexistência de produtos humanos já refutados e sua respectiva crítica teórica. Desde este movimento jorra um universo de possíveis gestados na práxis e segundo os sentidos inaugurados pelos praticantes da vida cotidiana.

Ao visitar as escolas, me deparei com uma vastidão de práticas, artefatos pedagógicos, recursos didáticos e tantas outras superfícies e movimentos com os quais poderia dialogar. Ao registrar o cotidiano escolar em imagens e selecionar uma delas para a conversação, o intuito não foi o de desvendar o artefato privilegiado. Neste

\footnotetext{
${ }^{5}$ Em Lefebvre (1967, p. 57) encontramos o "Quadro das Formas, dos Sistemas, das Estruturas" que contribuem na busca destas ideias humanas durante o momento analítico-regressivo do método regressivo-progressivo.

Rev. Diálogo Educ., Curitiba, v. 20, n. 66, p. 1462-1485, jul./set. 2020
} 
artigo, não tive por objetivo analisar o "semáforo do comportamento", mas provocar um diálogo que se aproxime do sentido das práticas escolares. Não se tratou, portanto, de uma análise deste artefato, mas de um breve estudo que aconteceu "através" deste artefato.

Durante a descrição, foram criadas narrativas datadas historicamente e relacionadas ao objeto observado, e isso faz pensar no que se mantém perenemente em outras práticas, objetos, instruções, modelos, estrutura e organização escolar. Ao olhar para um objeto fixado à parede de uma sala de aula e me entregar a conhecer, mesmo que parcialmente, as heranças que ele carrega, muito do que compõe o cotidiano escolar passou a representar um interesse especial para mim. Por exemplo: qual seria a função de um caderno destinado a cada disciplina escolar? Qual seria a história da fila para adentrar e sair de cada recinto da escola? Por que as carteiras são individuais e projetam uns de costas para os outros? De onde vem o currículo prescrito? Por que o recreio não é considerado tempo de aprendizagem? O que acontece quando o menino é orientado a ler um livro para fazer prova?

Poderíamos continuar a levantar outras perguntas simples sobre o cotidiano escolar, e para as quais muito facilmente ofereceríamos respostas. Curiosamente, o fato de serem perguntas simples e de conseguirmos respondê-las sem muita dificuldade não tem nos ajudado a resolver os problemas que expressam.

O questionamento direcionado ao uso de um artefato na sala de aula, embora não tenha resultado em uma resposta, buscou avançar em direção às heranças históricas, ao pensamento crítico e à invenção de possíveis. A observação, descrição, analogia e crítica de um mero artefato pedagógico deu a conhecer orientações presentes em sua planificação, execução e consumo. Estas orientações provenientes de outros tempos, ao se encarnarem no espaço escolar contemporâneo, dispõem de força para a manutenção de suas lógicas. Apesar de uma suposta ludicidade e de uma aparente neutralidade, muitos recursos didáticos, assim como também muitas práticas pedagógicas, carregam consigo as ideias de classificação, hierarquização, exclusão, centralidade do poder, silenciamento, colonialismo e tantas outras ideias que já criticamos e refutamos.

Estes objetos e práticas, contudo, não devem ser alvo de varreduras e banimentos do espaço escolar, pois que a extinção da coisa não apaga a ideia que a sustenta. A ideia retorna em outras roupagens (LACERDA, 2020). Na atualidade, as Rev. Diálogo Educ., Curitiba, v. 20, n. 66, p. 1462-1485, jul./set. 2020 
professoras têm acesso muito facilitado a modelos diversos que são replicados e aplicados em suas salas de aula. Naquilo que se copia, reside também uma concepção de mundo, de ensino-aprendizagem, de relação entre professora e alunos e outras tantas ideias que tomam carona nos clichês. Por isso, a constituição do espaço escolar deve partir das ideias, e não das coisas. Quando confecciona algo segundo um modelo externo, é possível que a professora sobreponha a coisa às suas próprias ideias. Talvez ela não perceba que, ao materializar o que foi proposto pelo outro, seu esforço se concentre na fidelidade ao modelo, em detrimento da inserção de concepções que privilegia. Eis o jogo: enquanto Certeau (1994) sinaliza as inventividades durante o consumo de um produto, Lefebvre (19991a) critica a persistência de algo indesejado naquilo que produzimos e reproduzimos.

É, pois, desde o conhecimento crítico acerca do mundo desejado, que é possível inventar outras práticas e outros objetos. Se para a professora a democracia, o diálogo, a solidariedade, a colaboração, a interação e tantos outros elementos são considerados essenciais, então que ela invente, junto com as crianças, um espaço orientado por práticas democráticas, dialógicas, solidárias, colaborativas e interacionistas, e que os objetos, atividades, linguagens, regras, relações sociais e tudo o mais que constitua este espaço, também seja orientado por este desejo coletivo.

Teríamos, então, uma escola para a criança habitar, enfim. Temos lutado há tempos por isso, e a História registra os embates continuamente travados para que tenhamos financiamento para a Educação, gestão democrática, diálogo com a comunidade escolar, valorização dos profissionais, currículos que sejam a expressão dos sujeitos, uma avaliação comprometida com o processo de aprender e tantas outras pautas de luta que têm sido frontalmente atacadas na história recente deste país. A luta pelo espaço escolar denuncia um lugar programado por uma racionalidade que não lhe é própria, mas que contém, no bojo daquilo que nos nega, as possibilidades de invenção e crítica para mudar a vida.

\section{Referências}

BARRIGA, Á. D. Uma polêmica em relação ao exame. In: ESTEBAN, M. T. (org.). Avaliação: uma prática em busca de novos sentidos. Rio de Janeiro: DP\&A, 1999.

CERTEAU, M. de. A invenção do cotidiano. Artes de fazer. Petrópolis: Vozes, 1994. 
FREIRE, P. Pedagogia da autonomia. São Paulo: Paz e Terra, 1997.

FOUCAULT, M. Vigiar e punir. Petrópolis: Vozes, 1987.

GEERTZ, C. A interpretação das culturas. Rio de Janeiro: LTC, 1989.

LACERDA, M. P. Os fantasmas ainda bailam: o método regressivo-progressivo e a escola. Revista Linguagens, Educação e Sociedade. Ano 25, n. 44, jan./abr. 2020.

LEFEBVRE, H. Metafilosofia. Prolegômenos. Rio de Janeiro: Civilização Brasileira, 1967.

LEFEBVRE, H. Perspectivas da Sociologia Rural. In: MARTINS, J. de S. Introdução Crítica à Sociologia Rural. São Paulo: Hucitec, 1986.

LEFEBVRE, H. A vida cotidiana no mundo moderno. São Paulo: Ática, 1991a.

LEFEBVRE, H. Critique of Everyday Life. v. 1. London: Verso, 1991b.

LEFEBVRE, H. A produção do espaço. Trad. Pereira, D. B. e Martins, S. (do original La production de l'espace). Paris: Éditions Anthropos, 2000. Disponível em: https://grupogpect.info/2014/06/02/livro-a-producao-do-espaco-de-henri-Lefebvre/. Acesso em: 15 set. 2016.

PERRENOUD, P. Não mexa na minha avaliação! Uma abordagem sistêmica da mudança. In: PERRENOUD, P. Avaliação: da excelência à regulação das aprendizagens. Entre duas lógicas. Porto Alegre: Artes Médicas Sul, 1999.

SARAMAGO, J. Ensaio sobre a cegueira. São Paulo: Companhia das Letras, 1995.

RECEBIDO: $22 / 04 / 2020$

APROVADO: $21 / 05 / 2020$

RECEIVED: 04/22/2020

APPROVED: 05/21/2020

RECIBIDO: $22 / 04 / 2020$

APROBADO: $21 / 05 / 2020$ 